\title{
PROPERTIES OF NANOCELLULOSE
}

\section{OBTAINED FROM SUGAR PALM (ARENGA PINNATA) FIBER BY ACID HYDROLYSIS IN COMBINATION WITH HIGH-PRESSURE}

\author{
HOMOGENIZATION
}

\author{
MYRTHA KARINA, ${ }^{*}$ RAHMAT SATOTO, ${ }^{*}$ AH. DAWAM ABDULLAH* ${ }^{*}$ and RIKE YUDIANTI ${ }^{* *}$ \\ "Research Unit for Clean Technology, Indonesian Institute of Sciences (LIPI), \\ Kompleks LIPI, Jalan Cisitu 21/154D, Bandung 40135, Indonesia \\ ** Research Center for Physics, Indonesian Institute of Sciences (LIPI), \\ Kawasan PUSPIPTEK, Tangerang Selatan 15310, Indonesia \\ ๔ Corresponding author: M. Karina, myrtha.karina.sancoyorini@lipi.go.id; myrtha.karina@gmail.com
}

Received May 24, 2019

\begin{abstract}
Nanocellulose was isolated from sugar palm (Arenga pinnata) fiber, using a combined treatment of acid hydrolysis and high-pressure homogenization. Sugar palm fibers (SPF) were initially pretreated with an acid solution to dissolve cellulose. Then, the aqueous solution of cellulose fibers $(0.2 \% \mathrm{w} / \mathrm{v})$ was passed through a high-pressure homogenizer at $20 \mathrm{MPa}$ during 15 cycles to provide sugar palm (SP) nanocellulose. The morphology and structure of SP nanocellulose was characterized using transmission electron microscopy (TEM), X-ray diffraction (XRD), Fourier transform infrared spectroscopy (FTIR), and CP/MAS ${ }^{13} \mathrm{C}$-NMR spectroscopy. The results showed that the acid hydrolysis of SP fiber, combined with high-pressure homogenization, produced nanocellulose with increased crystallinity, but it did not change the chemical structure of cellulose.
\end{abstract}

Keywords: nanocellulose, sugar palm fiber, physico-chemical treatment, properties

\section{INTRODUCTION}

Nanocellulose has received substantial attention in the last decade due to its promising characteristics, such as high active surface area and low cost. ${ }^{1,2}$ With its excellent properties, nanocellulose is applied for various utilization, such as for polymer composites reinforcement, ${ }^{3}$ drug delivery, ${ }^{4}$ conductive paper, ${ }^{5}$ transparent films ${ }^{6}$ and filter paper for virus removal. ${ }^{7}$

The properties of nanocellulose are highly dependent on the isolation techniques applied and on the raw materials. To obtain nanocellulose, chemical treatment is effective for delignification and hemicellulose solubilization. ${ }^{8}$ Much research effort has been done to isolate nanocellulose. Hydrolysis has been carried out to extract nanocellulose from wood flour, ${ }^{9}$ sugarcane bagasse ${ }^{10}$ sisal fiber ${ }^{11}$ and naturally white and colored cotton. ${ }^{12}$ Also, physical or mechanical treatment to isolate nanocellulose from wood, rice straw, ${ }^{13}$ potato, ${ }^{13}$ jute, ${ }^{14}$ sugarcane bagasse ${ }^{15}$ and wood dissolving pulp ${ }^{16}$ has been performed.
Moreover, the combination of chemical and mechanical treatment methods has been also investigated for obtaining nanocellulose from such sources as sugar beet pulp, ${ }^{17}$ hemp, ${ }^{18}$ water hyacinth fiber, ${ }^{19}$ kenaf, ${ }^{20}$ flax, ${ }^{21}$ banana racis, ${ }^{22}$ balsa tree, ${ }^{23}$ barks of Helicteres isora plant, ${ }^{24}$ wheat straw and soybean hull, ${ }^{25}$ corncorb, ${ }^{26}$ and pineapple leaf fiber. ${ }^{27}$

Sugar palm fiber is also considered as a potential source of nanocellulose. Nanocrystalline cellulose from sugar palm fiber was successfully isolated through delignification and mercerization treatments using $60 \mathrm{wt} \%$ concentrated sulphuric acid. $^{28}$ Other nanocrystalline celluloses were obtained from sugar palm fiber by treating it with sodium hypochloride, bleaching with sodium hydroxide and hydrolyzing with acid. The obtained nanocrystalline cellulose was further applied for manufacturing bionanocomposites. ${ }^{29}$ Moreover, nanofibrillated cellulose of sugar palm was obtained by several chemical pretreatment 
steps, such as pulping, bleaching, mercerization, finally followed by high-pressurized homogenization. ${ }^{30}$

In contrast to previous works, this study aimed to obtain nanocellulose from sugar palm fiber by simple acid hydrolysis, directly combined with high-pressure homogenization. The structural and physical-chemical properties of the nanocellulose were evaluated by transmission electron microscopy (TEM), X-ray diffraction (XRD), Fourier transform infrared spectroscopy (FTIR), and CP/MAS ${ }^{13} \mathrm{C}$-NMR spectroscopy.

\section{EXPERIMENTAL}

Materials

SPF was obtained from a private plantation in Ciburial, Dago Pakar, Bandung, West Java. The raw sugar palm fibers were cut to 2-3 cm length, washed thoroughly with running water to remove dirt, and airdried. The fibers were ground to pass a 100 mesh sieve.

\section{Treatment of cellulose fibers}

The dried SP powder was extracted with tolueneethanol $(2: 1, \mathrm{v} / \mathrm{v})$ in a Soxhlet apparatus to remove the extractives (TAPPI standard T $204 \mathrm{~cm}-97$ ), then filtered, washed with ethanol and oven dried $\left(50{ }^{\circ} \mathrm{C}\right.$ for $24 \mathrm{~h})$.

\section{Nanocellulose production}

Cellulose fibers were hydrolyzed with a $60 \mathrm{wt} \%$ sulphuric acid $\left(\mathrm{H}_{2} \mathrm{SO}_{4}\right)$ solution, at $45{ }^{\circ} \mathrm{C}$, for $30 \mathrm{~min}$ under continuous agitation. Hydrolysis was quenched by adding water, and then centrifuging. The resulted residue was suspended in water, followed by centrifugation. The process was repeated until constant $\mathrm{pH}$ was reached. A $0.2 \% \mathrm{w} / \mathrm{w}$ suspension of cellulose was homogenized using a laboratory disintegrator (Physcotron, Japan), with a rotational speed of 1550 rpm for 30 seconds. The disintegrated cellulose was then homogenized using a high-pressure homogenizer (Sugino, HJP 25001) at 20 MPA for 15 cycles. The resulted nanocellulose was kept at room temperature.

\section{Characterization \\ Morphology observation}

The morphology of SP cellulose after acid hydrolysis treatment was observed with a Miniscope1235, operated at accelerating voltage of 15 $\mathrm{kV}$. SP nanocellulose was also observed by a JEOL JEM 1200EX transmission electron microscope, operated at accelerating voltage of $80 \mathrm{kV}$.

\section{Particle size measurement}

The nanocellulose suspension of $5 \%(\mathrm{w} / \mathrm{v})$ was diluted in water at a ratio of 1:50 and ultrasonicated for $30 \mathrm{~min}$. The particle size was then measured using a particle size analyzer (Photal Otsuka Electronics ELSZ).

\section{$X$-ray diffraction (XRD) analysis}

The crystalline part of the samples was determined by XRD measurement on an XR diffractometer, with Ni-filtered $\mathrm{CuK} \alpha$ radiation at $45 \mathrm{kV}$ and $40 \mathrm{~mA}$. Samples were scanned at $2 \theta$ ranges varying from 5 to $40^{\circ}$ at a speed of $3 \% \mathrm{~min}$.

\section{Fourier transform infrared (FTIR) analysis}

Suspensions of nanocellulose were casted on Petri dishes, then oven-dried at $50{ }^{\circ} \mathrm{C}$, for $2 \mathrm{~h}$. Nanocellulose was prepared using the $\mathrm{KBr}$ pellet method. FTIR spectra were recorded using a Thermo Scientific Nicolet 155 FTIR spectrometer.

\section{Solid-state CP/MAS ${ }^{13} \mathrm{C}$-NMR}

Solid-state ${ }^{13} \mathrm{C}$-NMR spectra, with cross polarization/magic angle spinning (CP/MAS), were recorded on a $600 \mathrm{MHz}$ NMR spectrometer (150.95 $\mathrm{MHz}$ for ${ }^{13} \mathrm{C}$, Advance III, Brucker BioSpin $\mathrm{GmbH}$, Rheinstetten, Germany) at room temperature.

\section{RESULTS AND DISCUSSION \\ Morphology evaluation}

Figure 1 shows the microscopic image of SP cellulose, whereas Figure 2 shows the TEM image of SP nanocellulose. Figure 1 shows long and thick fibers, with the diameter ranging around 2-10 $\mu \mathrm{m}$, while the longest fiber was up to, or even more than, $200 \mu \mathrm{m}$. Meanwhile, the effect of high-pressure homogenization after acid hydrolysis of SP cellulose is shown in Figure 2. From the TEM image, it is clearly visible that the morphological structure of the SP cellulose changed drastically after the treatment. Long and thin fiber, either single or in bundles, can be clearly seen. Although some of the fibers are aggregated, individual fibers had the diameter in the range of 50-100 $\mathrm{nm}$. The existence of fiber bundles revealed by TEM is probably due to the incomplete removal of hemicellulose during the acid hydrolysis treatment, as also indicated by a previous study. ${ }^{22}$ However, current results suggest that the sugar palm fiber could be altered to its nano-dimension by the combination of acid hydrolysis and high-pressure homogenization.

\section{Particle size analysis}

The effect of high-pressure homogenization after acid hydrolysis on the particle size of SP fiber is shown in Figure 3. It shows that the particle size of SP cellulose obtained by hydrolysis treatment is in the range of 1000-4500 nm (Fig. 3A), 
whereas the particle size of SP nanocellulose (Fig. 3B) is in the range of $45-92 \mathrm{~nm}$. This result is in agreement with the findings regarding microcrystalline cellulose derived from Norway spruce (Picea abies) by sulfuric acid hydrolysis, followed by ultrasonic treatment, ${ }^{31}$ whose size

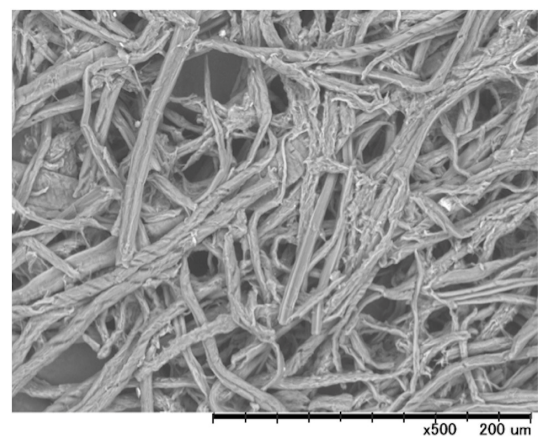

Figure 1: Microscopic image of SP cellulose

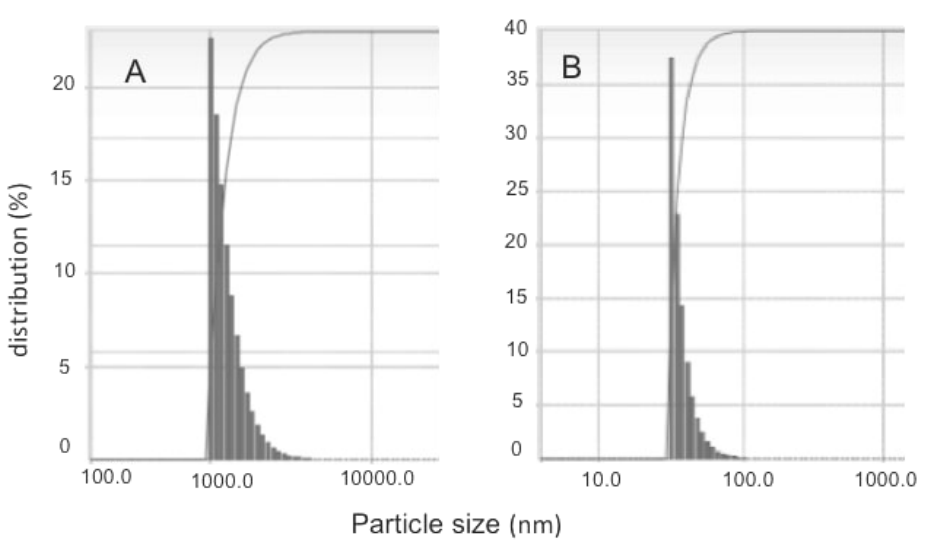

Figure 3: Particle size of SP cellulose (A) and SP nanocellulose (B)

Sugar palm fiber was also used in a previous study to obtain crystalline nanocellulose with a much lower size, of 3-18.19 $\mathrm{nm}$. The significant difference in the size of nanocellulose is probably explained by the different pretreatment, as the holocellulose was first converted to $\alpha$-cellulose, as well as by the higher pressure applied, of 50 $\mathrm{MPa}^{30}$

\section{X-ray diffraction (XRD) analysis}

X-ray diffraction spectra of SP cellulose are shown in Figure 4. The figure clearly reveals that a broad peak arises at $22^{\circ}$ for SP cellulose (A), indicating that the crystalline region represents the main structure. The subsequent treatment of was around 5-80 $\mathrm{nm}$. The results of the present study also show similarity with those achieved by other authors with regard to nanocellulose from sisal fiber, with a size of $30.9 \mathrm{~nm},{ }^{32}$ and from wheat straw soy hulls, with a size of $10-80 \mathrm{~nm} .^{33}$

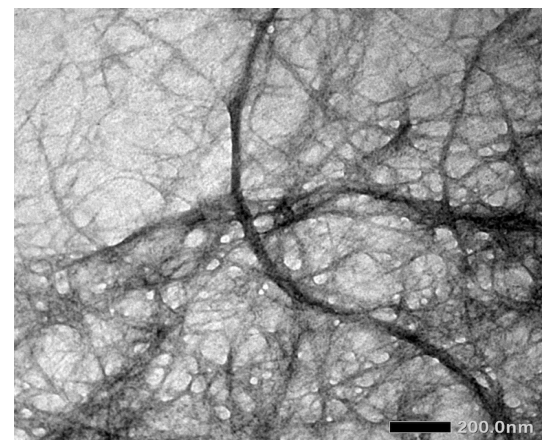

Figure 2: TEM image of SP nanocellulose

SP cellulose by high-pressure homogenization allowed the formation of cellulose I, since the doublet intensity in the main peak was not found $^{31,32}$ The diffraction peak at $22^{\circ}$ became sharper (B), revealing a rise in crystallinity. Intensive homogenization possibly realigned the cellulose structure and allowed the amorphous region of cellulose to split off the glycosidic bonds, ultimately liberating individual crystallites. The increase in the crystallite size was due to the increasing free motion after acid hydrolytic cleavage. ${ }^{33}$ Similar results have been achieved earlier for cellulose whiskers extracted from mulberry. ${ }^{34}$ 


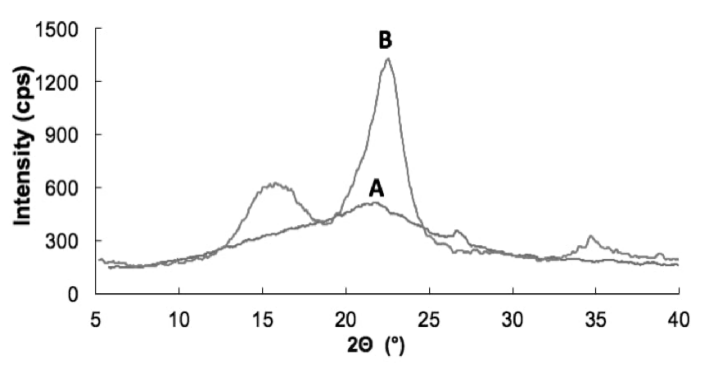

Figure 4: X-ray diffraction pattern of SP cellulose (A) and SP nanocellulose (B)

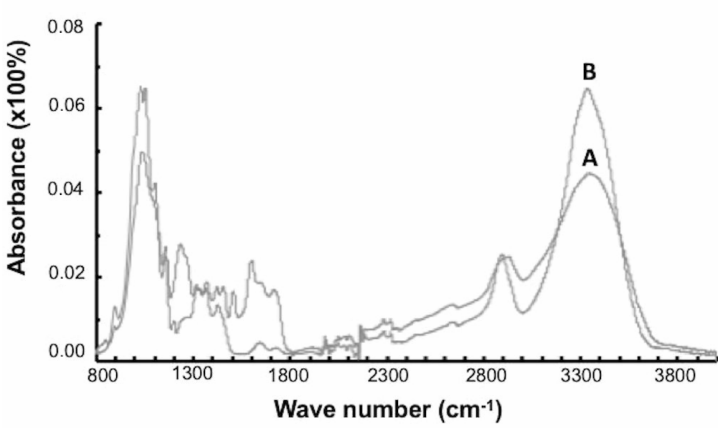

Figure 5: FTIR spectra of SP cellulose (A) and SP nanocellulose $(\mathrm{B})$

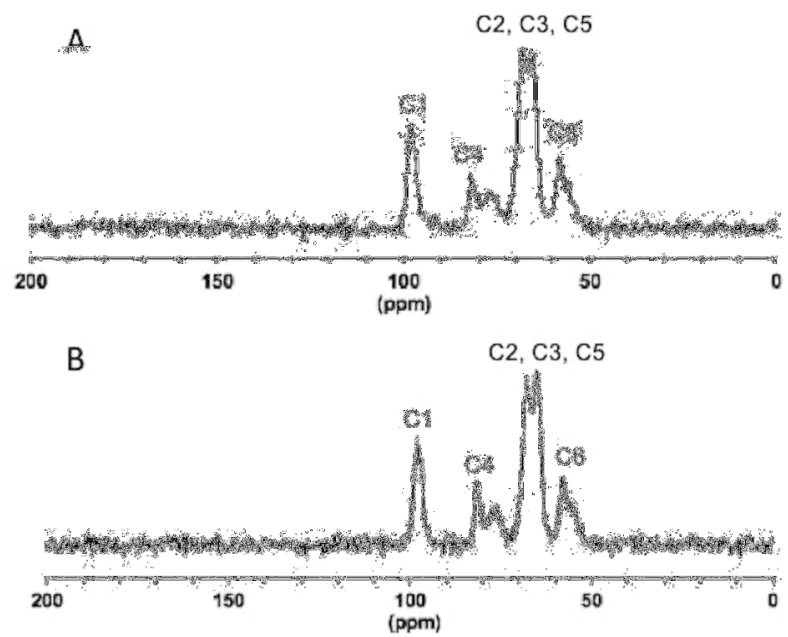

Figure 6: CP/MAS ${ }^{13} \mathrm{C}-\mathrm{NMR}$ of SP cellulose (A) and SP nanocellulose (B)

\section{FTIR analysis}

FTIR is a suitable technique for evaluating the chemical structure and its evolution as a result of any kind of chemical or physical treatments. FTIR spectra of SP cellulose are presented in Figure 5. The slight increase of the absorbance at $898 \mathrm{~cm}^{-1}$ is attributed to the typical structure of cellulose. ${ }^{34}$ The strong absorbance at $1040 \mathrm{~cm}^{-1}$ corresponds to the stretching vibration of $\mathrm{C}-\mathrm{H}$ in cellulose, ${ }^{33}$ whereas the band at $1230 \mathrm{~cm}^{-1}$ is related to the vibration of $\mathrm{COH}$ bending at $\mathrm{C} 6 .{ }^{35}$ The prominent peaks at 2890 and 3360 are attributed to $\mathrm{C}-\mathrm{H}$ symmetrical stretching and $\mathrm{OH}$ stretching, respectively. The peak observed at $3360 \mathrm{~cm}^{-1}$ is associated with the stretching vibration of $\mathrm{OH}$ in cellulose. ${ }^{34}$ From the analysis of the spectra, it may be concluded that high-pressure homogenization changed the intensity of the prominent absorption peaks, but it did not alter the cellulose structure.

\section{Solid-state ${ }^{13} \mathrm{C}$-NMR}

Solid-state CP/MAS ${ }^{13} \mathrm{C}$-NMR evaluation is a valuable method to investigate the morphology of cellulose. The ${ }^{13} \mathrm{C}$-NMR spectra of SP cellulose and SP nanocellulose are presented in Figure 6 A and $\mathrm{B}$, respectively. The peak correlated with $\mathrm{C} 2$, C3 and C5 appears at 60-72 ppm, while the chemical shift for $\mathrm{C} 6$ is at $58 \mathrm{ppm}$. It was observed that $\mathrm{C} 4$, attributed to the crystalline region, became sharper after the treatment by homogenization, thus demonstrating increasing crystallinity. This result is in accordance with the findings of the XRD analysis. Moreover, the appearance of a thin shoulder at the C6 peak is defined as belonging to the amorphous region and the disordered component of cellulose. This result is similar with those reported in a previous work, in which birch pulp, cotton linter and Cladophora $s p$. were used. ${ }^{36}$ From SP nanocellulose, it was noticed that the peak became sharper and the 
shoulder reduced faintly, suggesting the occurrence of cellulose degradation. This finding is similar to that reported by other authors regarding cellulose microfibers obtained from bagasse by the hydrolysis method. ${ }^{37}$

\section{CONCLUSION}

Sugar palm fiber was treated by acid hydrolysis, followed by high-pressure homogenization, to obtain cellulose and nanocellulose, respectively. Based on the characterization, it was concluded that the acid hydrolysis of SP fiber, combined with highpressure homogenization, changed the dimension of cellulose, to produce nanocellulose with increased crystallinity, but it did not alter the chemical structure of cellulose.

ACKNOWLEDGEMENT: The authors gratefully acknowledge Prof. Hiroshi Uyama (Graduate School of Engineering, Osaka University) for his support in carrying out this research. Appreciation is also addressed to Prof. Jun-Ichi Azuma for his assistance during the implementation of this work.

\section{REFERENCES}

M. A. Hubbe, O. J. Rojas, L. A. Lucia and M. Sain, Bioresources, $\quad 3, \quad 929 \quad$ (2008), https://ojs.cnr.ncsu.edu/index.php/BioRes/article/view/ BioRes_03_3_0929_Hubbe_RLS_Cellulosic_Nanoco mposites_Rev/0

B. H. Yano, J. Sugiyama, A. N. Nakagaito, M. Nogi, T. Matsuura et al., Adv. Mater. Res., 2, 153 (2005), https://doi.org/10.1002/adma.200400597

3 C. Miao and W. Y. Hamad, Cellulose, 20, 2221 (2013), https://doi.org/10.1007/s10570-013-0007-3

4 N. Lin and A. Dufresne, Eur. Polym. J., 59, 302 (2014),

https://doi.org/10.1016/j.eurpolymj.2014.07.025

5 Y. Tang, Z. He and J. Alexander, Cellulose, 21, 4569 (2014), https://doi.org/10.1007/s10570-0140418-9

6 H. Zhu, Z. Fang, C. Preston, Y. Li and L. Hu, Energy Environ. Sci., 7, 269 (2014), https://doi.org/10.1039/C3EE43024C

7 G. Metreveli, L. Wågberg, E. Emmoth, S. Belák, M. Strømme et al., Adv. Healthc. Mater., 3, 1546 (2014), https://doi.org/10.1002/adhm.201300641

8 J. X. Sun, F. Xu, X. F. Sun, B. Xiao and R. C. Sun, Polym. Degrad. Stabil., 88, $521 \quad$ (2005), https://doi.org/10.1016/j.polymdegradstab.2004.12.013 9 B. M. Nogi, S. Iwamoto, A. N. Nakagaito and H. Yano, Adv. Mater., 21, $1595 \quad$ (2009), https://doi.org/10.1002/adma.200803174

10 A. Mandal and D. Chakrabarty, Carbohyd. Polym.,
86, 1291

(2011),

https://doi.org/10.1016/j.carbpol.2011.06.030

11 J. I. Moran, V. A. Alvarez and V. P. Cyras, Cellulose, $\quad \mathbf{1 5}, \quad 149$ https://doi.org/10.1007/s10570-007-9145-9

12 E. D. M. Teixeira, A. C. Corre, A. Manzoli, F. D. L. Leite, L. Henrique et al., Cellulose, 17, 595 (2010), https://doi.org/10.1007/s10570-010-9403-0

13 K. Abe and H. Yano, Cellulose, 16, 1017 (2009), https://doi.org/10.1007/s10570-009-9334-9

14 M. George, E. Abraham, P. Jyotishkumar, H. J. Maria, L. A. Pothen et al., Int. J. Biol. Macromol., 81, 768

(2015),

https://doi.org/10.1016/j.ijbiomac.2015.08.053

15 J. Li, X. Wei, Q. Wang, J. Chen, G. Chang et al., Carbohyd. Polym., 90, $1609 \quad$ (2012), https://doi.org/10.1016/j.carbpol.2012.07.038

16 M. Gibril, T. Tesfaye, B. Sithole, P. Lekha and D. Ramjugernath, Cellulose Chem. Technol., 52, 711 (2018),

http://www.cellulosechemtechnol.ro/pdf/CCT9-

10(2018)/p.711-727.pdf

17 J. Leitner, B. Hinterstoisser, M. Wastyn, J. Keckes and W. Gindl, Cellulose, 14, 419 (2007), https://doi.org/10.1007/s10570-007-9131-2

18 D. Dai, M. Fan and P. Collins, Ind. Crop. Prod., 44, $192 \quad$ (2013), https://doi.org/10.1016/j.indcrop.2012.11.010

19 M. T. Sundari and A. Ramesh, Carbohyd. Polym., 87, 1701

(2012),

https://doi.org/10.1016/j.carbpol.2011.09.076

20 D. K. B. Lee, D. Hyun, K. P. Kang and J. Jeun, Cellulose, 23, 3039 (2016), https://doi.org/10.1007/s10570-016-1037-4

${ }^{21}$ E. H. Qua, P. R. Hornsby, H. S. S. Sharma, G. Lyons and R. D. Mccall, J. Appl. Polym. Sci., 113, 2238 (2009), https://doi.org/10.1002/app.30116

22 R. Zuluaga, J.-L. Putaux, A. Restrepo, I. Mondragon and P. Ganan, Cellulose, 14, 585 (2007), https://doi.org/10.1007/s10570-007-9118-z

${ }^{23}$ M. Mieko, N. Kumode, G. I. Muniz and W. L. E. Magalh, J. Clean. Prod., 149, 1157 (2017), https://doi.org/10.1016/j.jclepro.2017.02.083

24 C. Jose, J. Joy, L. Mathew, M. Mozetic, J. Koetz et al., Ind. Crop. Prod., 59, 27 (2014), https://doi.org/10.1016/j.indcrop.2014.04.020

25 A. Alemdar and M. Sain, Bioresour. Technol., 99, 1664 (2008), https://doi.org/10.1016/j.biortech.2007.04.029

26 C. Liu, B. Li, H. Du, D. Lv, Y. Zhang et al., Carbohyd. Polym., 151, 716 (2016), https://doi.org/10.1016/j.carbpol.2016.06.025

27 B. Mathew, A. Lopes, S. Ferreira, D. Souza, S. Thomas et al., Carbohyd. Polym., 81, 720 (2010), https://doi.org/10.1016/j.carbpol.2010.03.046

${ }_{28}$ R. A. Ilyas, S. M. Sapuan and M. R. Ishak, Carbohyd. Polym., 181, $1038 \quad$ (2018), https://doi.org/10.1016/j.carbpol.2017.11.045

${ }^{29}$ R. A. Ilyas, S. M. Sapuan, M. R. Ishak and E. S. 


\section{MYRTHA KARINA et al.}

Zainudin, Carbohyd. Polym., 202, 186 (2018), https://doi.org/10.1016/j.carbpol.2018.09.002

30 R. A. Ilyas, S. Mohd, R. Ibrahim, H. Abral, M. Roslim et al., J. Mater. Res. Technol., 8, 2753 (2019), https://doi.org/10.1016/j.jmrt.2019.04.011

31 D. Bondeson, A. Mathew and K. Oksman, Cellulose, 13, $171 \quad$ (2006), https://doi.org/10.1007/s10570-006-9061-4

32 J. I. Moràn, V. A. Alvarez, V. P. Cyras and A. Vàzquez, $\quad$ Cellulose, $\quad \mathbf{1 5}, \quad 149 \quad$ (2008), https://doi.org/10.1007/s10570-007-9145-9

33 A. Alemdar and M. Sain, Bioresour. Technol., 99, 1664

https://doi.org/10.1016/j.biortech.2007.04.029
34 R. Zuluaga, J. Putaux, A. Restrepo, I. Mondragon and P. Gañán, Cellulosa, 14, 585 (2007), https://doi.org/10.1007/s10570-007-9118-z

35 M. Fan, D. Dai and B. Huang, in "Fourier Transform - Materials Analysis", edited by S. Salih, IntechOpen, 2012, pp. 46-68, https://doi.org/10.5772/35482

36 K. Wickholm, P. T. Larsson and T. Iversen, Carbohyd. Res., 312, 123 (1998), https://doi.org/10.1016/S0008-6215(98)00236-5

37 D. Bhattacharya, L. T. Germinario and W. T. Winter, Carbohyd. Polym., 73, 371 (2008), https://doi.org/10.1016/j.carbpol.2007.12.005 